Original Research Paper

\title{
Opportunistic Behavior as Behavior Manipulations
}

\author{
${ }^{1}$ Elena Yakovleva, ${ }^{2}$ Natalia Grigoryeva and ${ }^{3}$ Olga Grigoryeva \\ ${ }^{1,3}$ Institute of Economics, Management and Law, Kazan, Russia \\ ${ }^{2}$ Institute of Management, Economic and Finance, Kazan (Volga Region) Federal University, Kazan, Russia
}

\author{
Article history \\ Received: 13-01-2016 \\ Revised: $13-07-2016$ \\ Accepted: 26-09-2016 \\ Corresponding Author: \\ Natalia Grigoryeva \\ Institute of Management, \\ Economic and Finance, Kazan \\ (Volga Region) Federal \\ University, Kazan, Russia \\ Email: Almarus@yandex.ru
}

\begin{abstract}
The study of opportunistic behavior in relation with manipulation techniques is important because it directly affects the efficiency of agent's relationship. We identified two forms of opportunistic behavior that depend on the subject composition of the contractual relationship. In the article we attempt to identify significant techniques of manipulation of information. It is important to understand real nature of opportunism in contractual relationship. The study proved the high importance, because it expands our knowledge about the nature of exogenous opportunistic manifestations as a society and economic phenomenon.
\end{abstract}

Keywords: Opportunistic Behavior, Manipulation of Information, Techniques of Manipulation, Forms of Opportunistic Behavior, Macroeconomics, Institute of Trust, Mem, Information Asymmetry

\section{Introduction}

Interpretation of the economy as a set of transactions, where participants enter into contractual relations concerning various assets in order to implement their inherent targets, inevitably leads to the recognition of the objectivity of the prerequisites of opportunistic behavior as a form of implementation of the interaction of economic agents.

Sources of opportunism occur at all stages of development of human civilization, regardless of the dominant type of economic structure and the nature of government. This is shown in economic science, which is independent of the initial principles of the study of the world, recognizes the existence of different forms of opportunistic behavior and offers tools to prevent of its consequences for society as a whole or for individual subjects.

Differences in approaches to the interpretation of opportunism, which are due to the peculiarities of methodological platforms studies and are expressed in the conceptual framework, analytical tools, content, methodological approaches and practical guidelines, do not prevent the recognition of the thesis on the revitalization of opportunistic behavior in modern society and the enlargement of its subjects. This provision is of particular importance for the Russian economy, structural transformation of which led to the formation of a qualitatively new institutional environment and the formation of target participants under the influence of the laws of the market economy. Thus were created the conditions for opportunistic behavior at the micro, meso-and macro levels of the economic system, which is characterized by the presence of general and specific properties.

The basic assumption of neoclassical theory, namely the recognition of excellence of information and the absolute rationality of economic agents, does not allow to identify the causes of opportunism and to formulate instruments aimed at its prevention. In the institutional concept, opportunism is understood as a result of the breach of contract due to incompleteness of information or information distortion and inefficiency of the institutional environment, which entail high transaction costs of overcoming adverse selection and the decline of social welfare.

The similar approach allows explaining the reasons for the wide spread of opportunism in the modern Russian economy, where there are numerous institutional voids and institutional traps, inefficient mechanism of enforcement of contracts and the reluctance of economic agents to abide by the existing rules of conduct. Not the last role in the current state of affairs has the process of manipulating information, which is quite common in the context of opportunistic behavior that requires philosophical reflection.

We emphasize that opportunistic type of behavior takes place in situations where one agent uses information asymmetry to his advantage (Williamson, 1985 ) with the aim of unilateral redistribution of benefits from the transaction, thus pointing to the practices of manipulation. Opportunism may manifest itself in various aspects, including personal, corporate, regional 
(Garifova and Kundakchyan, 2014), national and international levels, which requires an interdisciplinary approach in its study.

Analysis of numerous publications on the opportunistic behavior shows that issues related to its manifestations, are important to representatives of various economic schools and research areas. Significant contribution to the development of theoretical positions about the opportunism was introduced by (Williamson, 1985; Galbraith, 1958; Becker, 1992; Akerlof, 1994; Veblen, 1992; Volchik, 2004; Bodrov, 2014; Lumineau and Quelin, 2012; Rodriguez et al., 2002).

The analysis of numerous publications devoted to the problems of opportunistic behavior shows that the issues associated with its manifestations are the center of attention of representatives of various economic schools.

Beginning the study of opportunistic behavior of economic agents was initiated in the works of representatives of the classical school of political economy, which is considered a separate form of its.

In the second half of the XX century in the framework of institutional theory $\mathrm{O}$. Williamson introduced the modern definition of opportunistic behavior.

In the study of various aspects of the behavior of economic agents, a significant contribution was also made by (Shleifer, 2005; Akerlof, 1994; Rothschild and Stiglitz, 1976).

The results of a study of the impact of opportunism on the level of public welfare was represented in the works of (Becker, 1992) and etc., the relationship of opportunism and adverse selection-in the writings of (Akerlof, 1994) tools management software deals in models of signals and filtering-in the writings of (Rothschild and Stiglitz, 1976) and others. Opportunistic behavior in correlation with the dynamics of transaction costs is studied in the works of (Holmstrom and Milgrom, 1991; Furubotn and Richter, 2005), etc.

Institutional approach to the study of opportunistic behavior is implemented in the works of foreign ((Alchian, 1972; Veblen, 1992; Galbraith, 1958; Commons, 1934; Coase, 1964; Davis and North, 1971) and others) and Russian authors ((Auzan, 2007'; Katishev and Polterovich, 2006; Shastitko, 1996), etc.).

In Russian economic thought certain aspects of opportunistic behavior is investigated in the works of (Bogdanova, 2009; Bodrov, 2014; Volchik, 2004; Korolev, 2007; Popov and Simonova, 2005), etc.

Significant contribution to the study of the behavior of economic agents was introduced by (Kahneman, 2003) and etc.

The $\mathrm{n}$ diverse spheres of life are addressed in a number of works by Russian and foreign researchers ((Abdeev, 1994; Kara-Murza, 2009; Pocheptsov, 2000; Lull and Lin, 1981; Shaw and McCombs, 1977), etc.).
The approach to organizational relations from the point of view of opportunistic behavior was first described in the paper "Positive Accounting Theory" in 1986, which states that managers can manage profits in order to maximize their own benefit, by influencing contracting parties and stakeholders (Sun and Rath, 2008).

Watts and Zimmerman (1978) first used the category of opportunism to explain the behavior of managers when announcing their profit margin by influencing the results of contractual relations, aiming thus to have influence on wages and bonuses paid by the manager, the shareholders.

Opportunistic behavior is also considered by some researchers as discrimination of some participants in the economic process on the part of their counterparties (Harbaugh and To, 2013).

Meanwhile the analysis of manipulative practices of opportunistic behavior is a scientific lacuna. Problems of their study are that the facts of manipulative behavior of economic agents themselves are nonobvious and, as a consequence, are difficult to prove. In this regard, to solve the problems of economic theory and practice it seems relevant to study patterns of implementation of opportunistic behavior as one of the clearest manifestations of manipulative experience which will allow a broader view of the processes of interaction of economic agents when making their market transactions at all levels.

\section{Materials and Methods}

The aim of the study is the analysis of opportunistic behavior in relation with manipulation techniques, the problem of learning manipulative practices used by the subject that implements opportunistic actions in the implementation of plans known only to him.

Information base of research were monographs and articles devoted to the problems of opportunism and manipulation, the official websites of Transnational Corporations (TNCs) and their annual reports and other program documents posted on the Internet. As main methods of research, the authors have chosen an analytical, logical, phenomenological, systematic, theoretical and empirical.

In this study, we will try to identify manipulation techniques which will help to understand patterns of opportunistic behavior in contractual relationships.

\section{Results}

The main subjects of socio-economic processes at the international level are the states, representing the national economy as well as Transnational Corporations (TNCs). The transactions at the global level can be attributed as a transaction of sale between consumers (firms and households) and TNCs; and the 
situation where the state as an economic agent establishes restrictions for residents to conduct transactions with non-residents.

Each of these types of transactions can create the preconditions for opportunistic behavior by its participants, the implementation of which, when available, is one of the preconditions of behavior, which cannot be completely ruled out.

In this study, we consider the manipulation process in the framework of opportunistic behavior and examples of its implementation at the international level that is relevant in current modern times, affecting the socioeconomic and political situation.

In modern times, the entire cultural continuum is served by technology and cultural phenomena have a certain level of technology of creation and distribution. To the greatest extent it relates to information: Today it stands as "something which causes to know" and "is passed through the digital clarity of knowledge", giving rise to "universal hallucination of truthfulness of Evil" (Baudrillard, 2000).

In this regard, some aspects of information and its dissemination in socio-cultural space through technology have negative traits. First, let's highlight the problem of formation of the distorted/false knowledge, through which the manipulation of consciousness and the zombification people occures. Here is a particular duality of the situation. On the one hand, today there is freedom in the functioning and distribution of media. However, false/distorted information, constantly broadcasted by the media and the Internet, violates the rights and freedoms of a person on receiving reliable information. Moreover, in the modern cultural space, every person has the right to freely express himself or herself and to speak, but this free expression acquires an unprecedented scale, with distorted shapes.

Today practically anyone may get into the focus of media attention may, but his intellectual and ethicaesthetic components are a big problem. Most often the image of man caught in the circulation and the meaning of his information is false, simulation and/or immoral. As a result of the imposition of such information submitted attractively and truthfully, people are losing the critical ability of judgment and the possibility of forming their own opinions. Such a situation is aggravated by information and communication technologies of manipulation of consciousness, which are impossible to resist: Manipulation is now acquiring the global scale and constantly improving, is complicated. The power of the information field of the media and the Internet becomes total: It is impossible to hide and it is difficult to resist, because it is, especially in the framework of opportunistic behavior, skillfully veiled. This forces us to turn to the analysis of manipulation techniques.
The term "manipulation" originally meant agile handling objects with hands with a purpose; skilled fraud associated with the distraction from the hidden. We emphasize that dictionaries and encyclopedias emphasize the idea of the power in nature of manipulation. So, in New York "The modern dictionary of sociology" emphasizes that "...this is the kind of power application at which one has the affection the behavior of others, without disclosing the nature of the conduct which he expects from them". Kara-Murza (2009) draws attention to the fact that manipulation is associated with "programming the views and aspirations of the masses, their moods and even mental state to ensure their behavior, which is necessary for those who owns the means of manipulation". In general, almost all researchers identify in the phenomenon such features related to the management/manipulation of consciousness, as the negative and the latent impact that requires dexterity, skill and knowledge.

Due to these characteristics there is achieved a stunning effect of mass belief in manipulation, which can be anything from a worldview, paradigm, lifestyle, idea, value, person, thing, etc. Moreover, today manipulation practices have the aesthetic aspect: The information is "nicely packaged" (verbally and visually), creating the illusion of appealing to each recipient, which functions as temptation and seduction. Again, it leads to ethical issues related to the violation of humans rights and freedoms. Nevertheless, today in almost every cultural sphere borrowed from politics the Machiavellian principle "the end justifies the means" dominates and the ethical dimension is ignored. In the end, people are either puppets or the audience of specially choreographed theatrical spectacle and society itself is transformed into a "society theatre".

Let us deal systematically with the technology of manipulation of information in the context of opportunistic behavior.

Because of manipulation of consciousness, through information there is a mixture of real and fictional, existing and imaginary, so one of the best designs that can accommodate such knowledge, is a myth that hides the real knowledge and subdues a large numbers of people.

The fact is that modern myths are a mixture of contradictory elements-magic and technical thinking. It is no coincidence that today there appear mythtechnologists (directors, image-makers, correspondents, reporters, PR-technologists), systematically and rationally producing mythologized texts in the right aspect, which in their content reflect false reality. It is facilitated by the new electronic infrastructure (media, television, virtual reality), which transform reality in media-reality which is often far from phenomenological reality. Modern myth-technology through the media and 
Internet design and pass the necessary authoritative opinion which is absorbed by a huge number of people. As the result, people think that they have their own opinion, actually being imposed, which leads to the formation of false thinking. As written by E. Fromm in his book "Escape from freedom" (1941), “...people think that they make decisions, that they want something, while in reality they succumb to the pressure of external forces, internal or external conventions and "want" exactly what they have to do." This statement reveals the idea of power in nature of manipulation, which imperceptibly introduce certain ideas/values, subduing huge masses.

Today artificially created and imperceptibly introduce myths distort reality, conceal the true state of things, distracting people from reality and focusing on profitable for the creators and their customers cultural (political, economic, religious, scientific and other) senses. As rightly noted by Baudrillard (2000), "in modern society there are only implausible, unlikely events", "before, the purpose of the event was to happen, now-to be made". Mind control with myth is intensively used in such fields as politics, economy, science, religion, advertising, everyday life, where through the manipulation of power structures certain goals achieve quickly and effectively.

The next example of manipulation in the framework of opportunistic behavior is a strategy of recipients' seduction. To do this, the opportunist creates attractive mythological text, which is able to "capture" the audience. Here reveals itself the use of "eternal stories"myths (e.g., the story about Heaven and Hell, disasters, global conspiracy, struggle for power, the trickster, the Superman-loner, the Prince and the pauper, Cinderella, etc.). Within these stories there are raised the issues of power and submission, dependence and freedom, justice and equality, wealth and poverty, good and evil, health and sickness, love and hate, friendship and betrayal. They ensure "rating" of customers (politicians, scientists, public figures and media people) and media (television and radio channels, newspapers and magazines).

Means of the strategies of seduction are the verbal and visual aspects of texts.

Manipulation of information by the subject to the opportunistic behavior is associated with the change in language features, where the emphasis is made on the emotional component, which is most pronounced in such a "unit of cultural information" as a meme (by K.R. Dawkins, "the selfish gene" (Dawkins, 1989)). The latter, having a high degree of virulence, multiplies rapidly, finding itself in Internet, media, advertising, everyday life and other spheres. The popularity of the meme promotes the fact that it includes not only the words and thoughts (mostly meaningless), but the visual segments that easily and naturally perceived by modern "society theatre". Pursuing a key goal of introduction of certain information to the masses, opportunist as a mythotechnologist writes catchy, easy to remember, instilled in memory slogans, calling attention to information and making to remember it. Moreover, there are created the texts representing the lace tie of words which meaning is difficult to grasp or is missing, so these texts give rise to preconditions for multiple interpretations.

For rising attractiveness of the texts with myth elements and their successful implementation opportunists-technologists create new words and often change or distort the meaning of the old ones. In this case words and phrases are saturated with feeling and forceful emotions. Moreover, the cultural and the text box gets a huge number of foreign words, which meaning remains unclear for the majority. People "rush" on impressive-sounding foreign words, incorporate them into their lexicon, but their meaning is not interesting to them. These words gradually capture the cultural space, displacing the familiar words of the "great Russian language", which in the end is defeated.

Most vividly emotional-persuasive power of the word is represented in the political and economic promotions, media materials and advertising. So, the creators of advertising slogans assume that advertising is the "engine of trade". They understand that "the ability to sell a "product" by person, to find language and forms of advertising" becomes a demand (Hakobyan, 2011). Thus, writers of slogans are not concerned about the quality of the advertised goods: Ethical aspect of the problem is removed. Moreover, they also do not care about the meaning of the slogan, which often has a "zero degree meaning". Here other laws related to the economic background and the cult of money come into play. In advertising, people are encouraged by hyperesthetic, glamorous and polished "truth about lies" or "lies about truth", fascinating by the effective accompanying slogan with the use of unclear or distorted words, but having emotional-visual energy.

In advertising texts the emotional emphasis of the speech is made on important topics of human existence: For example, the feeling of pleasure ("Nissan Almera. Pleasure without delay"), prestige ("Ford Excursion. A symbol of your superiority"), image ("You are better!", "Toyota. Manage year dream"), the present ("Audi. The superiority of high technologies", "Rhythm In Vogue"), eroticism ("The Ideal form is always with You"). Attractive slogans with word play: "Free-Volvo", "Salamander: Each pair on the pair," "“Doctor Mom": Song of the illness will be short". Popular slogans, drawn to the sense of taste ("Mars"-all will be in chocolate"), as well as operating a humorous note and lifting the mood of the person ("Xerox. We taught the world to copy").

Such visualization elements enhance the efficiency of the technology of implementation. The fact is that the 
modern era is "the age of the image" that has limitless possibilities thanks to the visualization of any cultural segment and its components with the use of high technology, able at any moment to change the image format at the request/demand of the customer. The visual element changes the principle of constructing the image and its perception. Video image created using the avatar technology is active: It can be viewed in its entirety, from all sides and kept in memory. Herewith image is both similar and not similar to itself: It all fits the modern standard, intentionally uterus its aesthetic or ugly quality, thereby allowing one to manipulate the perception of the recipients and convert it. Today images attack people from everywhere: Any information stories (political, economic, scientific and other), media materials, advertising are illustrated by the visuals.

Visual component is associated with the use of certain techniques that enhance the manipulation. So, computer graphics blurs the line of real and fantasy, with the help of a computer "Windows" can simultaneously display multiple storylines or development options, the real and the imaginary world, past, present and future, young and old.

Visualization of culture contributes to the emergence of a special kind of aesthetics-polyaesthetics, thanks to which the recipient has the ability of tempting a choicebetween: Based on his taste and mood, but experiencing indifference for the simultaneously perceived/stories/ texts. The mentioned above contributes to the appearance of a mosaic type of thinking which is quite superficial and not lingering anywhere for long, which is a lightheadedness, total indifference and apathy of recipients taking all that into consideration, but not reflexing over the situation, perhaps because of the endless string of seductive choice-betweens. The result is a new mythological reality, which is far from reality, but perceived as true (note, "each has his own"). We will emphasize the recent evidence that the myth becomes cramped in its own cultural framework and it begins an active expansion in socio-cultural space.

An essential element of the technology of manipulation through information used by opportunist can be called prophecy. The reason is that modern opportunists have mastered the art of managing people, according to which it is much easier to controllable not by physical methods, but by the power of imagination. Modern opportunist, acting as a predictor, promises something wonderful in the form of the "Golden century" or creepy, eschatological, thus tipping the audience to choose his way.

Another element of the technology of manipulation is the creation of the image, due to which rises and sacralizes this or that person/brand/company. Image is associated with imagination, including not as much the natural properties of the personality, as specially developed, creatively crafted with the help of PRtechnologies, which people perceive as a result of their own vision. In this regard, the image gives the object additional mythological characteristics, seeking to distinguish it from other similar ones. In the words of Losev (2001), the object is granted the miracle. But today, "obscene arrogance" often reigns in the image as wonderful and prominent (Girenok, 2010).

It should be noted that the image creates a certain socio-psychological setting because it is perceived by the recipient as a result of his own vision and not as something imposed from the outside. These properties of the image allow the opportunist to use it as a tool of mind control. But the image turns man into impersonal, "partial person", having "empty", "without properties" body: "Now, "the person without properties" is intensively cultivated" thanks to visually-screen culture (Kutyrev, 2006). The fact is that the technical reality of screens and surfaces creates copies of people who are much better than the original. Man as a natural person dies, creating artificial character, even the simulacrum, the living theatre, show.

Often leaders/popular people of modern culture which involve opportunistic behavior, demand to be worshiped like the Gods of antiquity. Specially revived/created rituals associated with idol worship, raise the importance of the person/brand/company and support their image. So the cult of hero worship is linked to the performance of certain rituals: Entering the fan club, collecting paraphernalia and information, ecstatic delight at the mentioning of the name, etc. For example, musical, economic, or political Olympus "stars" confirm their divinity by compiling a detailed rider list, specifying the requirements for the organizers of the performances. Companies/brands create certain tag days associated with significant dates, hold events raising their prestige and attracting new clients. Efficiency of constantly "played out" rituals is that they support the core myth and lull the sense of personal and individual responsibility of citizens, their activity, integrity and critical judgment. Today, as in ancient times, in various fields of culture rituals are used as a means of aggrandizement of power, coercion and imposing people certain actions.

Significant and attractive elements of the manipulation, eagerly perceived by modern "society theatre", include the design of media productions (political, scientific, religious, economic, etc.) with the already-made-fictional-image. These performances are nothing but "vain feigned attempt to create some kind of life beyond that which already exists", which ultimately contributes to the "indifference to its existence" (Baudrillard, 2000). Media performance is a flexible system without a detailed dramaturgical plan, but thanks to the media and the Internet, it instantly becomes the 
property of the masses, without any doubt. These attractive performances are made by the elements of secrecy, innuendo, miracle, unpredictability, shock value, scandal that are possible thanks to the mythical texts, image and technical effects of visualization. Modern passive type of consumer takes all that into consideration today, without reflecting on the situation. The fact is that the created digital image is selfsufficient: It "quietly fills the inner world and becomes a condition of perception, the censor is acceptable or unacceptable, visible, conspicuous or departed into the shadows, pushed out, ignored" (Savchuk, 2012). The result is a new situation, not when people think the images, but rather images think/manipulate people.

Here are some specific examples related to the process of manipulating information in the context of opportunistic behavior.

So, German concern "Volkswagen" in September 2015 acknowledged the use of the software in 11 million cars with diesel engines, the algorithm of which was intentionally built for low emissions of harmful substances during certification testing (Rauwald and Jennen, 2015). Understatement of the corresponding data as an element of mythisation contributed to a more competitive performance of cars "Volkswagen" from the point of view of consumers, which potentially contributed to sales and increased revenue to the automaker, leading to additional benefits. In annual reports the $\mathrm{CO} 2$ emissions given in section of the main indicators with positive dynamics (" $\mathrm{CO} 2$ emissions European new car fleet in $\mathrm{g} / \mathrm{km}$ " and " $\mathrm{CO} 2$ emissions in kg/veh.”) (Volkswagen, 2014). In addition, the protection of the environment as a separate section of the report, which also focuses on the emission of carbon dioxide into the atmosphere. Back in 2012 at the motor show in Geneva, the head of the concern has declared intention to achieve a $30 \%$ reduction of emissions in engines by (Interfax, 2015).
The user of diesel vehicles were misled and the concern had actually abused the trust of this category of customers (Fig. 1, a simple form of opportunism, abuse of trust). Since the concern "Volkswagen" is a transnational Corporation with revenue from sales (sales revenue) 202,458 million euros for 2014 (Volkswagen, 2014), an abuse of trust is an example of opportunistic behavior on the international level by the firm as an economic agent.

The scandals associated with the identification of the facts of opportunistic behavior on the international level, more political in nature. So, researchers believe that the existence of problems in the tests for measuring emissions of substances of concern "Volkswagen" seen for a long time. However, the conflict broke out right now, which indicates its advantage to some participants in the global policy. Therefore, often in a variety of transactions at the international level, there are involved third parties who are interested in a particular outcome of the relationship, although they do not directly participate. Implementation of opportunistic actions in this case and the flow of information is reorganized and presented in Fig. 2.

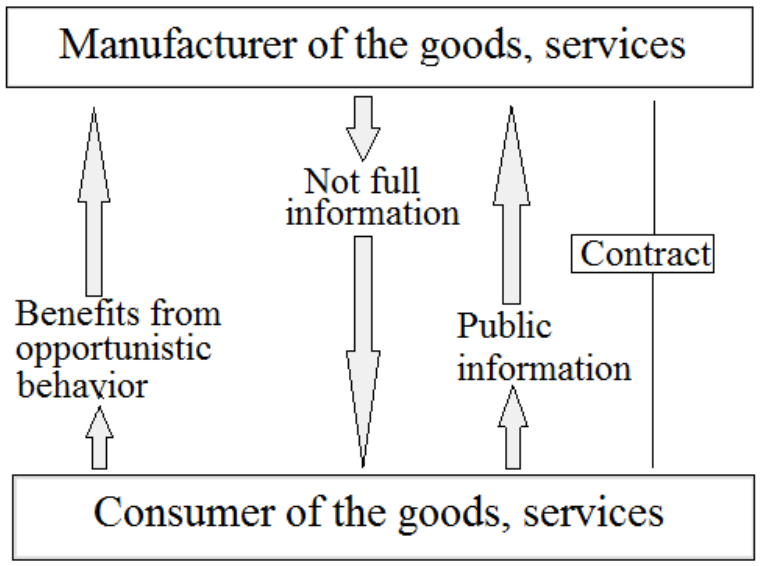

Fig. 1. Breach of trust as a form of opportunistic behavior

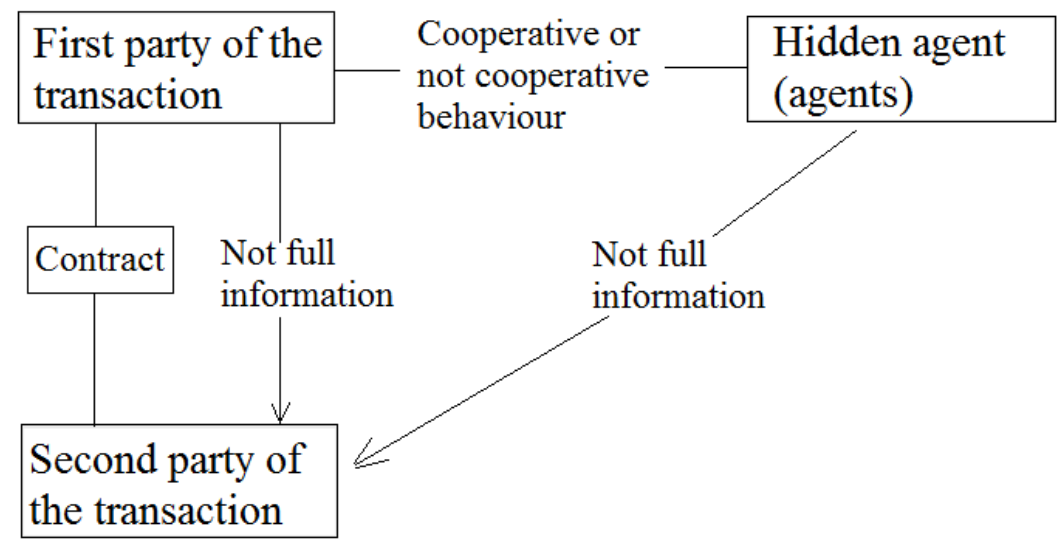

Fig. 2. The presence of a hidden agent as a form of opportunistic behavior 
Similar points to the fact that the development of economic processes on global, supra-national level largely depends on political factors, including the impact influencing the development indicators of the local industrial markets.

In addition, the state as a large and significant economic agent can also act as an agent in the implementation of opportunistic acts against other States or specific business entities (companies). An example of such behavior is, in particular, sanctions.

As a result of studying examples of opportunistic behavior at the international level revealed that exogenous precondition for opportunism is the existence of a conflict of interests when implementing formal or informal contractual relationship. Implement an economic agent of opportunistic actions at the international level is the protection of economic and geopolitical interests. As conditions of realization of opportunism as a behavioral manipulation are the veiled presence of information asymmetry and the possibility of its long-term maintenance.

\section{Discussion}

In modern society socio-technological relations and ways to implement them are more related to technology. Moreover, these technologies are inherent not only to the economic phenomena, manufacturing process, etc., but also in cultural phenomena. The result is considered in the trends, it is obvious that cultural phenomena also appear in certain technologies of creation and distribution. This increases the importance of identifying, understanding and accounting for behavioral manipulation for different types of economic behavior. Thus, considered in the technology of manipulating information in the context of opportunistic behavior is important not only for opportunistic behavior, but also important for understanding the motives of other human behaviors. Opportunistic behavior was chosen for studying primarily at a large number of gaps in the knowledge about the regularities and peculiarities.

Carmaker Volkswagen announced the issuance of $\$ 1,000$ to each owner of a car with a diesel engine, the software which underestimated the actual emissions of harmful substances during testing, which allowed to circumvent the strict ecological standards of the USA.

According to the Associated Press, the group announced the beginning of such action to the owners from the US, where the proposal received 482 thousand owners of problematic cars. The customers of the group will be able to get a Bank card with a face value of $\$ 500$. This money can be spent on any purpose. A gift card for another $\$ 500$ you can only use the dealership of the concern-for purchases or payment of services

International rating Agency Fitch downgraded longterm Issuer default rating Volkswagen to $\mathrm{BBB}+$ from $\mathrm{A}$ with a negative Outlook. According to a press release of the Agency, the short-term rating of the automaker downgraded to F2 from F1.

Overall, the damage from opportunism may include both explicit costs in the form of actual financial loss to the economic agent (e.g., penalties) and implicit costs in the form of reputational losses (goodwill).

The trust level and localization of transactions, reduce the risks of opportunistic behavior due to the formation of a personalized relationship of trust between economic agents and to establish local "rules of the game".

The development of competition, understood as the driving force of economic development (Filosofova and Bykov, 2012), is intended to stimulate economic growth and market methods to correct the existing imbalances in the structure of production. The development of competition would contribute to greater uncertainty in economic relations. At the same time, increasing risks of economic activity can be compensated by the development of a system of property rights protection and the independence of the judiciary (institutional measures).

However, researchers note the presence of administrative distortions of competition in the Russian economy. It is proposed to consider the competitive environment as a set of economic, constitutional and new constitution rules described in the framework of formal or informal institutions (Sadriev and Mullakhmetov, 2015).

For many years the world community is implementing projects on creation the common market, integration of the economies of different countries to reduce barriers to competitive displacement flows of goods, services and capital (the Customs Union, the EU-funded project, the North American free trade area etc.). There are created supranational associations and organizations to solve problems in the field of international trade (particularly WTO, membership in which entails the abolition of many measures aimed at supporting non-market methods of domestic producers). However, each country is interested in the maximum possible support of domestic producers of the residents and providing them with more favorable conditions than for non-residents. In turn, the violation of measures to limit protectionist measures is a consequence of opportunistic behavior on the international level. An interesting fact is that any dispute involving the breach of the rules of GATT, has not been submitted to the international court of justice. A specific prohibition against appeal parties of the GATT-47 in the international court of justice in the GATT did not contain. It follows that the disputing parties apparently did not see practical sense in transferring their dispute under the GATT-1947 in the UN international court in connection with the effectiveness procedures of the GATT. 


\section{Conclusion}

In modern times information has the powerful nature, being used in the framework of opportunistic behavior and replicating through the media and the Internet, thereby penetrating into the consciousness of many people and manipulating them. Modern information in the framework of opportunistic behavior is a specially designed, rational, well-thought-out design, designed to inspire people, to encourage and guide their actions. Technology of manipulation of information by the trimmer includes such features as the use of myth and mythologies, emotional role of language, the visualization element, the prophecy, image, media rituals and performances.

Losing the sense of individuality, people exposed to manipulation by the technology of myth-making, begin to act, think and feel in a certain specified way. It is a similar effect sought out by the creators of the myths, trying to deprive people of the sense of reality, their own uniqueness and personal responsibility, freedom and independence of thinking. The technology of modern myth-making contributes to the fact that the myth speaks favorable and relevant construct in all fields of culture that have a powerful impact on the minds and souls of modern times. The combined effects of elements of technology of modern myth-making generates in society a certain type of thinking, which creates a view and opinion about a particular era, event, politician, phenomenon or thing.

Through the use of technology a myth or a phenomenon is a phenomenon showing itself (according to M. Heidegger, the "self-in-itself-shown" (Heidegger, 2003)), or an apparent phenomenon (according to $\mathrm{M}$. Heidegger, the "self-so-itself-by-itself-apparent"). That is, the myth becomes a form of culture, which incorporates both positive and negative pulses. Much depends on the customer and the identity of mythotechnology, creating a new reality and setting its direction. If their image is a copy of the hero of the novel by (Eco, 2012) "The Prague cemetery" Simonini Simonini-a man whose ability for mythology intertwine with superstition, narrowness, immorality, insidiously, the commercialism, the future bears the stamp of discord, unrest, wars, trumped-up fraud, not with historical accuracy. The reality will disappear. As a result of technological creation and implementation of myths the reality is blurred and even disappears in the consciousness of many people: The person begins to live in created mythologized reality, looking at everything through the prism of myths imposed on him, enjoying this and not solving the real life problems.

The technology of manipulation violates human rights related to liberties and the right to receive accurate information. Technology of manipulation of information is a threat: The man turns into a puppet, alienated not only from others but also from himself, becoming passive and non-reflective subject of sociocultural space. Knowledge of components of manipulative practices in the framework of opportunistic behavior, despite their concealment, helps to understand the situation and to block, at least partially, the impact of manipulation. It is the knowledge of manipulation of information which helps relieve flair of wonderfulness, restoring the person to the fold of rational and real perception of the world. With this knowledge a person can hold the demarcation line between myth and reality, fictional and actual. But, unfortunately, most people today are not ready for this: They have lost the ability of judgment, living in a consumer society according to the principle of to Have and not to Be. Minding the modern mess in media the situation can be corrected only by the introduction of censorship and the establishment of certain committees, each relying on material quality, accuracy and compliance with reality.

\section{Acknowledgement}

The researchers thank to colleagues for the valuable discussions during the development of this study.

\section{Author's Contributions}

Elena Yakovleva: Provided analysis of manipulative techniques and contributed to the writing of the manuscript.

Natalia Grigoryeva: Designed the research plan and organized the study. Analysis and contributed in the writing of manuscript.

Olga Grigoryeva: Participated in all experiments, coordinated in data-analysis and contributed to the writing of the manuscript.

\section{Ethics}

This article is original and contains unpublished material. The corresponding author confirms that all of other authors have read and approved the manuscript and no ethical issues involved.

\section{References}

Abdeev, R.F., 1994. The Philosophy of Information Civilisations. 1st Edn., Vlados, Moscow, pp: 36.

Akerlof, G.A., 1994. The market for "lemons": Quality uncertainty and the market mechanism. Q. J. Econom., 5: 91-104.

Alchian, A., 1972. Production, information costs and economic organization. Am. Econom. Rev., 62: 777-795. 
Auzan, A.A., 2007. Institutional Design of Reforms: Experience and Forecast Attempts: Working Paper WP10/2007/09. 1st Edn., State UniversityHigher School of Economics, Moscow, pp: 24.

Baudrillard, J., 2000. The Transparency of Evil. 1st Edn., Dobrosvet, Moscow isdat, pp: 259.

Becker, G., 1992. The economic way of looking at life. Department of Economics, University of Chicago.

Bodrov, O.G., 2014. Main causes of Staff labor opportunism in organizations. Life Sci. J., 11: 400-408.

Bogdanova, N.Y., 2009. Opportunistic conduct: On the formulation of the concept. Sci. J. VolSU, Ser. 7. Philosophy, 2: 199-204.

Coase, R.H., 1964. The regulated industries: Discussion. Am. Econom. Rev., 54: 194-197.

Commons, J.R., 1934. Institutional economics. New York.

Davis, L.E. and D.C. North, 1971. Institutional change and American economic growth. Cambridge University Press, Cambridge.

Dawkins, R., 1989. The Selfish Gene. 1st Edn., Oxford University Press, Oxford, ISBN-10: 0192860925, pp: 352.

Eco, U., 2012. The Prague Cemetery. 1st Edn., Windsor, Bath, ISBN-10: 1445878240, pp: 567.

Filosofova, T.G. and V.A. Bykov, 2012. Competition, Innovation. 1st Edn., Textbook, Competitiveness.

Furubotn, E.G. and R. Richter, 2005. Institutions and Economic Theory: The Contribution of the New Institutional Economics. 1st Edn., University of Michigan Press, Ann Arbor, ISBN-10: 0472030256, pp: 653 .

Galbraith, J.K., 1958. The Affluent Society. 1st Edn., Houghton Mifflin, Boston, pp: 368.

Garifova, L. and R. Kundakchyan, 2014. Quality of life as a factor of socio-ecological and economic assessment. Mediterranean J. Social Sci., 5: 95-100. DOI: $10.5901 / \mathrm{mj}$ ss.2014.v5n18p95

Girenok, F., 2010. Fun to Think Otherwise. 1st Edn., Academic Project, Moscow, pp: 137.

Hakobyan, K., 2011. Legalizacija science. Domestic notes.

Heidegger, M., 2003. Philosophical and political writings. M.Stassen.

Harbaugh, R. and T. To, 2013. Opportunistic discrimination. Forthcoming, European Economic Review.

Holmstrom, B. and P. Milgrom, 1991. Multitask principal-agent analyses: Incentive contracts, asset ownership and job design. J. Law, Econom. Organ., 7: 24-52.

Interfax, 2015. The engineers at Volkswagen have used the emissions of the engines for fear of the authorities.

Kahneman, D., 2003. Maps of bounded rationality: Psychology for behavioral economics. Am. Econom. Rev., 93: 1449-1475.
Katishev, P.K. and V.M. Polterovich, 2006. Policy of reforms, initial conditions and transformational recession. Econom. Math. Methods, 42: 5-18.

Kara-Murza, S.G., 2009. Power of Manipulation. 1st Edn., Academic Prospectus, Moscow, pp. 380.

Korolev, A.I., 2007. Trends in opportunistic behavior in conditions of disequilibrium economy.

Kutyrev, V.A., 2006. The Philosophy of Postmodernism. 1st Edn., Progress Publ., Berlin, pp: 51.

Losev, A.F., 2001. Dialectics of myth. Moscow. Publishing House "Mysl".

Lull, J.Y.S. and C.S. Lin, 1981. Optimum path planning for mechanical manipulators. J. Dynam. Syst. Meas. Control, 103: 142-151. DOI: 10.1115/1.3139654

Lumineau, F. and B.V. Quelin, 2012. An empirical investigation of interorganizational opportunism and contracting mechanisms. Strategic Organ., 10: 55-84. DOI: $10.1177 / 1476127011434798$

Popov, Y.V. and V.L. Simonova, 2005. Endogenous opportunism in the theory of the principal-agent. Economy, 3: 118-131.

Pocheptsov, G.G., 2000. Psychological Wars. 1st Edn., Kiev: "Refl-book", Moscow.

Rauwald, C. and B. Jennen, 2015. German probe found more indications of elevated diesel pollution.

Rodriguez, M.A., J.E. Ricart and P. Sanchez, 2002. Sustainable development and the sustainability of competitive advantage: A dynamic and sustainable view of the firm. Creativity Innov. Manage., 11: 135-146.

Rothschild, M. and J. Stiglitz, 1976. Equilibrium in competitive insurance markets. Q. J. Econom., 80: 629-650.

Sadriev, R.D. and H.S. Mullakhmetov, 2015. About the problem of distortions of competition in the Russian economy. Econom. Bull. Kazan, 3: 10-17.

Savchuk, V.V., 2012. The philosophy of the era of new media. Prob. Philosophy.

Shastitko, A.E., 1996. The new theory of the firm. Moscow, TEIS Publ.

Shaw, D.L. and M.E. McCombs, 1977. The Emergence of American Political Issues: The Agenda-Setting Function of the Press. 1st Edn., West Pub. Co., St. Paul, ISBN-10: 0829901426, pp: 211.

Shleifer, A. 2005. Understanding regulation. Eur. Financial Manage., 11: 439-451. DOI: $10.1111 / \mathrm{j} .1354-7798.2005 .00291 . \mathrm{x}$

Sun, L. and S. Rath, 2008. Fundamental determinants, opportunistic behavior and signaling mechanism: An integration of earnings management perspectives. Int. Rev. Bus. Res., 4: 406-420.

Veblen, T., 1992. The theory of leisure class. An Economy of Institutions.

Volchik, V.V., 2004. The Evolutionary Paradigm and the Institutional Transformation of the Economy. 1st Edn., University Press, Rostov, pp: 295. 
Elena Yakovleva et al. / American Journal of Applied Sciences 2016, 13 (9): 996.1005 DOI: 10.3844/ajassp.2016.996.1005

Volkswagen, 2014. Sustainability Report. URL.

Watts, R.L. and J.L. Zimmerman, 1978. Towards a positive theory of the determination of accounting standards. Account. Rev., 53: 112-134.
Williamson, O.E., 1985. The Economic Intstitutions of Capitalism. 1st Edn., Simon and Schuster, ISBN-10: 068486374X, pp: 468. 